\title{
Advances in non-Newtonian dam break studies
}

\author{
N Moon Golder Associates Pty Ltd, Australia \\ M Parker Golder Associates Pty Ltd, Australia \\ HJJ Boshoff Golder Associates Pty Ltd, Australia \\ D Clohan Golder Associates Ltd., Canada
}

\begin{abstract}
Tailings dam failures have and continue to cause large-scale devastation and environmental impacts. Historically these impacts have largely been predicted using Newtonian hydrodynamic modelling principles resulting in a general overestimation of potential consequences. However, since about 2014 the collective mining industry began developing complex tools to better predict the likely impacts of these failures. The industry has focused on leveraging the latest in computational flow dynamics modelling software and computational hardware to preform non-Newtonian tailings dam break assessments. However, as our tools become more sophisticated so does the requirement on input data. This paper discusses the past modelling approaches and the development of non-Newtonian tailings dam break models. The sensitivity of the flow behaviour is presented through four case studies, showing how this selection influences the outcomes and how previous approaches assuming Newtonian characteristics may present an overly conservative result. It is noted that additional knowledge and expertise will become available as non-Newtonian tailings dam break studies become the norm. In the interim, the uncertainty of these analysis needs to be analysed.
\end{abstract}

Keywords: Newtonian, non-Newtonian, tailings, dam break, modelling

\section{Introduction}

Mining operators have an increased need to understand the potential risk of mine waste facilities, following recent catastrophic and high-profile tailings dam failures that impacted downstream environments and communities. Shareholders and insurers, who have seen the devastating effects of these failures also demand an increased understanding of the potential risks and assurance that these risks are managed as low as reasonably possible. Managing these risks includes the development of operational plans, emergency plans, exclusion zones, mitigation measures, flood protection structures etc. Improving the accuracy of modelling assist mine designers and planners to avoid overly conservative decision-making or development of unnecessary flood protection infrastructure. Notwithstanding, with the increased awareness of dam safety more mining operators are adopting best practice guidelines such as the Canadian Dam Association's (CDA) Dam Safety Guidelines (CDA 2013) with a view for better practice for tailings dam management (Ker 2016).

Regulators and governing authorities are demanding more detailed information, additional considerations (Mining for Sustainable Development Programme (M4SD) 2017) or compliance with enacted approvals processes (Department of Environment and Energy 1999) during the assessment of mining applications involving tailings dams. This is observed with approval processes becoming more strenuous, requiring Engineers of Record to provide detailed design considerations and impact assessments, which are based on guidance provided by industry bodies such as the CDA Dam Safety Guidelines (CDA 2013) and Australian National Committee on Large Dams Incorporated (ANCOLD 2012).

\section{$2 \quad$ Advances in non-Newtonian modelling}

In response to the demand to better understand and predict tailings failure slurry fluid behaviour, there have been many advances in the field of modelling the dynamics of fluids, of which modelling non-Newtonian 
substances has taken a leap forward in recent years. This includes improving the estimation of tailings runout distances and the accuracy of the estimations (Martin \& Akkerman 2017), which are critical to any ongoing analysis of a potential tailings dam failure. Computational advances along with laboratory testing are redefining understanding of rheological characteristics and behaviour of breached tailings flows (Fontaine \& Martin 2015). As such, modelling and mapping software applications are drastically changing the way engineers can analyse and estimate the potential impacts from a tailings dam failure.

The following is a summary of the advances observed in recent years:

- Increased computational power using either graphics processing units (GPUs) and/or cloud computing (Marwa et al. 2014).

- Multi-domain (nested) models with higher resolution around areas of interest.

- Increase in number of software modelling packages.

- Integration of 2D-3D coupled models (More 2011).

- Enhanced graphical user interfaces that increase efficiency and allows for more complex modelling set-ups.

- More efficient computational fluid dynamics (CFD) coding techniques, which reduces the computation time.

Figure 1 presents some of these advancements in a timeline indicating that the majority of the CFD modelling advances occurred in the past 10-20 years, noting that FLOW-3D ${ }^{\circledR}$ (Flow Science, Inc. 2018) was available in the 1970s, however was not used for dam break assessments until 2014.

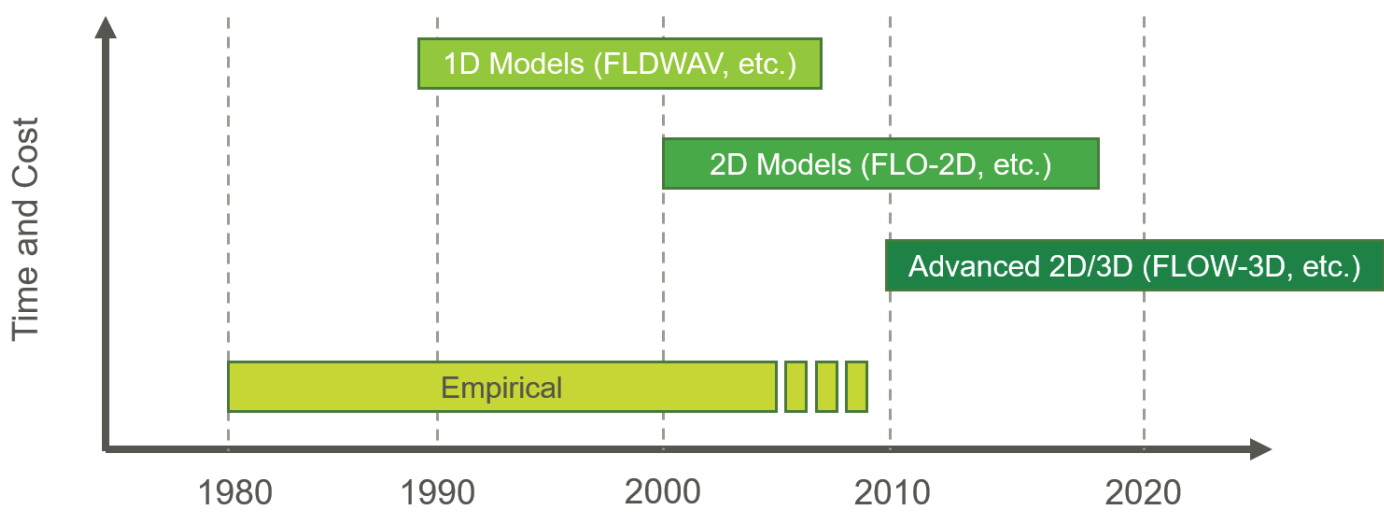

Figure 1 Advances in non-Newtonian flood modelling

\section{Discussion}

\subsection{Difference in Newtonian versus non-Newtonian fluid behaviour}

Fluids are said to be Newtonian fluids if they obey Newton's Law of Viscosity, where shear stress is linearly proportional to the deformation rate (shear rate) based on its respective viscosity. Shear stress is related to a fluid's apparent viscosity by the following equation:

$$
\tau=\eta \frac{d u}{d y}
$$

where:

$$
\begin{aligned}
& \tau=\text { shear stress. } \\
& \eta=\text { viscosity. } \\
& \frac{d u}{d y} \quad=\text { deformation rate or shear rate. }
\end{aligned}
$$


For Newtonian fluids, the ratio of shear stress to shear rate is a constant called viscosity. However, for non-Newtonian fluids, and those fluids which do not obey Newton's Law of Viscosity, this relationship is not constant; as such, this relationship is call apparent viscosity. This is illustrated in Figure 2 for four typical fluid types: Newtonian, Bingham plastic, pseudoplastic and dilatant fluids.

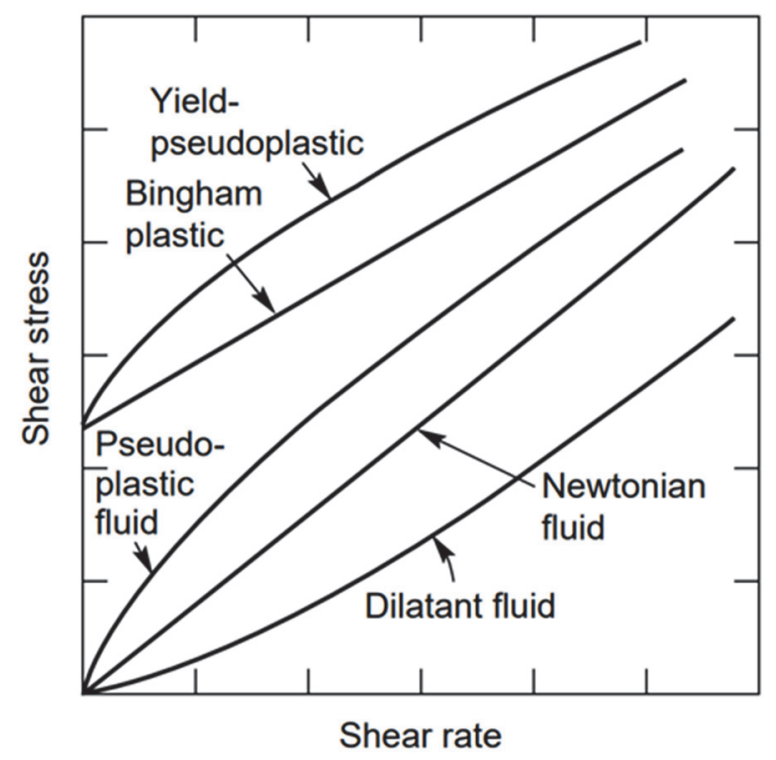

Figure 2 Illustration of shear stress as a function of shear rate (Chabbra \& Richardson 1999)

Tailings typically exhibit yield-pseudoplastic (shear thinning) characteristics (Blight \& Bentel 1983; Horsley \& Snow 1988), where the apparent viscosity decreases with increasing shear rate. Additionally, these fluids, which have a solids concentration typical of a non-Newtonian fluid, require a minimum shear stress (yield stress) before flowing as a fluid. Tailings therefore exhibit very different behaviours to water (Newtonian fluid) at increased shear rates and should be considered for estimating inundation areas when conducting a dam break assessment.

\subsection{Modelling approach}

The modelling approaches-when conducting a Newtonian or non-Newtonian dam break assessment-are largely similar, with the exception that a clear understanding of the properties of the tailings is required to model the non-Newtonian behaviour.

A typical approach in conducting a non-Newtonian dam break assessment is presented in Figure 3.

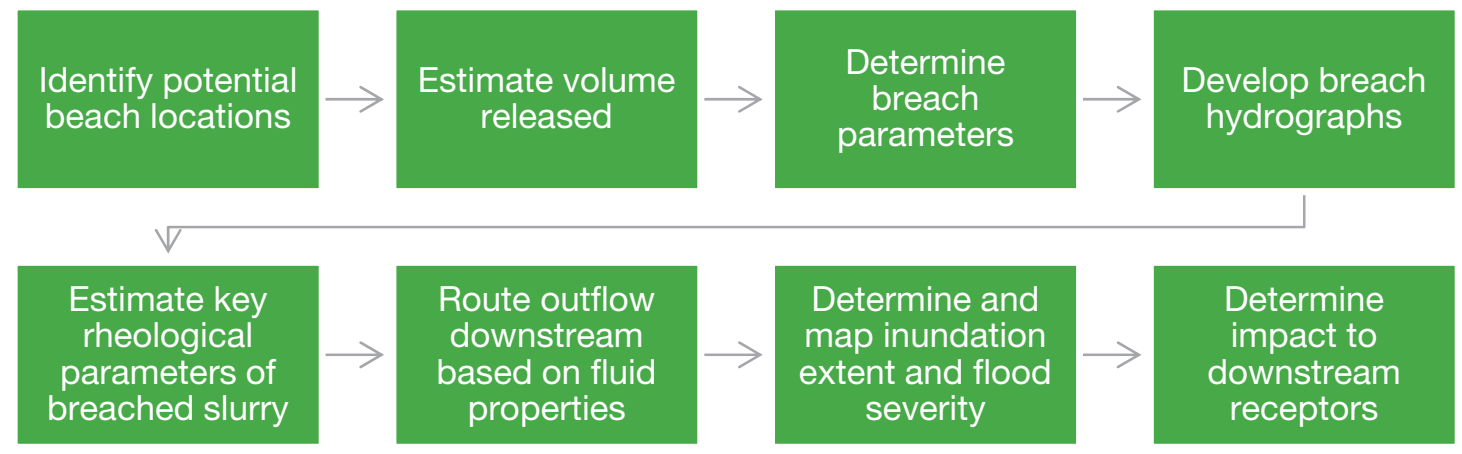

Figure 3 Overview of typical dam break assessment approach

The two main levels of uncertainty in non-Newtonian assessments are around the estimation of volume released and the estimation of rheological parameters used in the assessment. 
Other information, such as potential breach locations and identification of downstream receptors are typically better understood using site survey information, tailings dam embankment details, aerial imagery and topographical information (Strauss et al. 2016). This information is generally available or can be obtained cost-effectively.

\subsection{Rheology parameters}

As shown in Figure 3, additional consideration to define material rheology is required when conducting a non-Newtonian assessment. Some laboratory tests may therefore be required to obtain the key parameters to allow for better simulation of the non-Newtonian fluid behaviour. This could be challenging to obtain and might still not represent the tailings material at the base of the storage or the material mobilised during a flood failure event. As an alternative, published values could be used as an estimate with an adjustment applied to reflect the uncertainty in the form of a sensitivity analysis.

Fluid behaviour within a modelling package capable of modelling non-Newtonian flows, such as FLOW-3D ${ }^{\circledR}$ (Flow Science, Inc. 2018), is represented by a relationship between apparent viscosity and the deformation rate. The Herschel-Bulkley equation can be used to describe this relationship, as shown in Equation 2 (Mehta et al. 2018), from which the apparent viscosity can be calculated using Equation 1.

$$
\tau=\tau_{0}+K\left(\frac{d u}{d y}\right)^{n}
$$

where:

$$
\begin{aligned}
\tau_{0} & =\text { yield stress. } \\
K & =\text { consistency index. } \\
n & =\text { power law exponent. }
\end{aligned}
$$

\subsection{Volume released}

Due to the non-Newtonian characteristics of tailings material, all material above the beach base may not be mobilised during a failure event. It must be noted that estimating the volume of tailings released during a hypothetical tailings dam breach is inherently complicated due to the level of uncertainty associated with such an analysis. As such, published literature indicates that the percentage of stored tailings released ranges from between 1 and 100\%, with a reported average of between 20 and 40\% (Clemente et al. 2013; Larrauri \& Lall 2018).

When estimating the potential volume of tailings released during a tailings dam breach, the following conceptualisation is generally considered:

- Material characteristics of the stored tailings and whether the tailings are consolidated and spatially heterogenous.

- Presence of a supernatant pond above tailings material.

- The failure mode which initiates the dam failure, e.g. whether failure is caused by a storm event ('flood failure') or by piping without a rainfall event ('sunny day failure').

Numerical modelling of the tailings outflow process would increase the accuracy in estimating the volume of tailings released during a breach. However, current commercially available technology is not fully capable to undertake such detailed modelling with several simplified methodologies available for estimating the volume of tailings released, including statistical regression, flowability approximation and geometric approaches.

The tailings outflow volume can also be estimated by considering the post-failure tailings slope and using a conical failure to estimate released volume. This approach assumes a failure surface that radiates upstream from the breach location at an upward average slope (post-failure tailings slope). Studies by Blight and Fourie (2003) indicate that failure slopes typically vary between 3 and $7 \%$, however can be up to 17 to $33 \%$ in certain locations. Observations from a small selection of historical tailings dam breaches by Rourke and Luppnow 
(2015) indicates that post-failure tailings slopes are typically in the range of 5 to $18 \%$. An illustration of a failure cone is presented in Figure 4.

\section{Profile View}
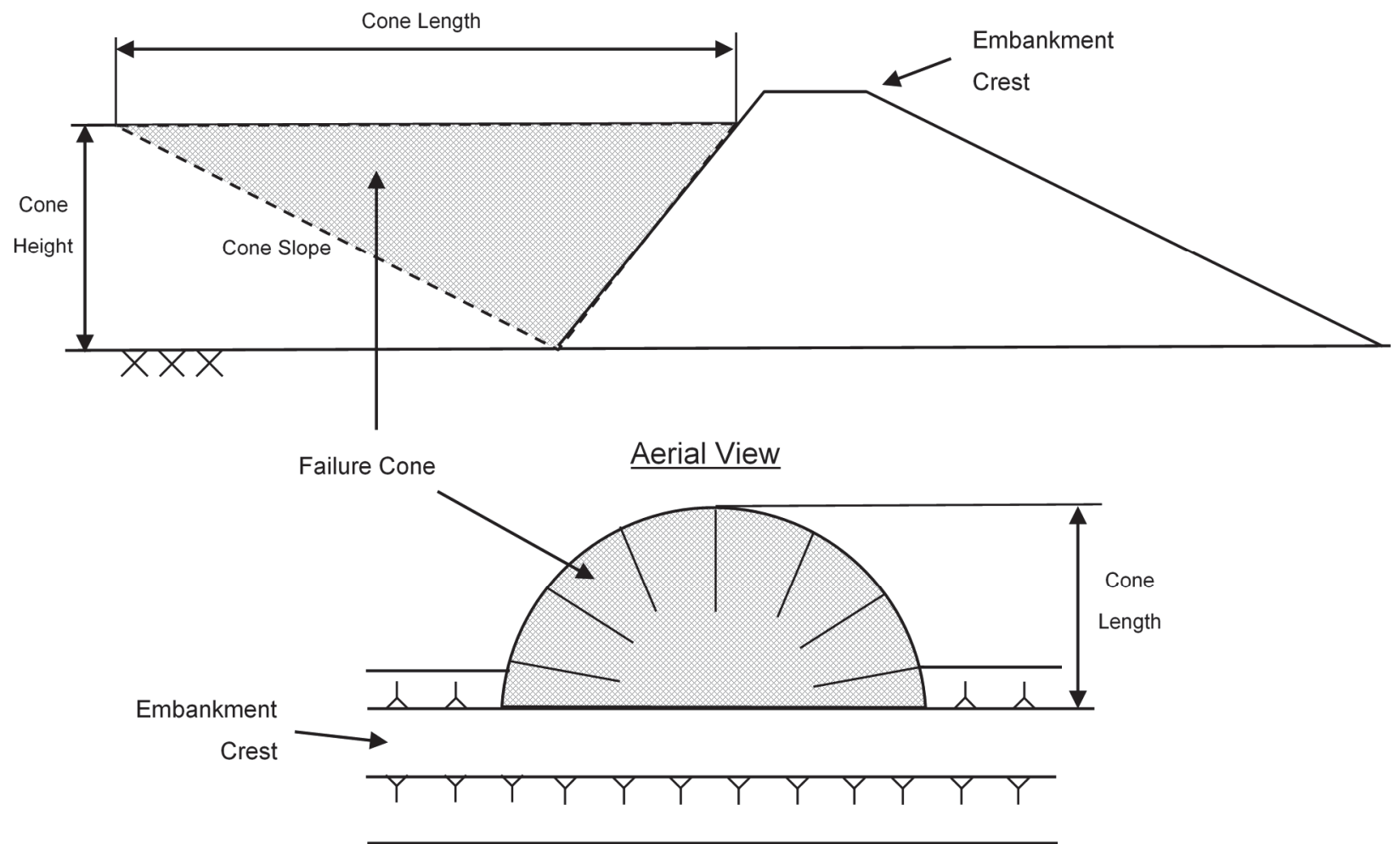

NOT TO SCALE

\section{Figure 4 Overview of typical dam break assessment approach}

The failure slope estimate can be refined by considering site specific tailings rheology and by use of post-liquefaction strength estimates, such as the cone penetration test (Robertson 2010).

In addition to the material properties of the tailings, other factors such as embankment condition and extent of water residing on top of the tailings can have an impact on the overall volume of tailings released. It is therefore critical to consider the site-specific aspects of a tailings dam when estimating its potential release volume during a failure event.

\subsection{Hydraulic routing}

Hydraulic routing of the estimated tailings outflow volume can be undertaken using a CFD modelling package, such as FLOW-3D ${ }^{\circledR}$ (Flow Science, Inc. 2018), which considers material properties for determining the likely fluid behaviour after release.

CFD modelling packages can estimate the apparent viscosity given a relationship based on shear rate, as discussed previously. Shear rate varies across the flow domain both spatially and temporally, therefore the analysis of non-Newtonian flow can become rather complex.

In addition to the fluid rheology and behaviour, the resulting outflow is largely related to the down-gradient terrain and presence of watercourses within the impacted area. It is therefore difficult to estimate the runout distance using empirical approaches. 
CFD modelling removes some of the uncertainty present with traditional Newtonian and empirical approaches. This allows for better estimation of impacted areas based on the aspects already described. The case studies presented in Section 3.7 have been assessed using FLOW-3D ${ }^{\circledast}$ (Flow Science, Inc. 2018).

\subsection{Associated advantages/disadvantages}

Moving towards a CFD modelling approach revealed several advantages, and a few disadvantages.

Advantages:

- Analysis of multiple scenarios including representation of increased risk profile.

- Sensitivity analysis of assumed parameters and the effects of climate change.

- Better estimation of impacted area and therefore less overly conservative flood protection measures.

- Visualisation of the tailings runout and better estimation of flood arrival times to inform stakeholders and develop meaningful emergency procedures.

Disadvantages:

- Depending on the software application the modelling requires suitable hardware to achieve reasonable runtime.

- Models can run for a number of days without providing a complete result, which also depends on the software application and the complexity of the model.

\subsection{Case study}

There are a number of sensitivities in the completion of tailings dam failure impact assessments with flow behaviour, rheology and release volume all impacting the final results. The sensitivity of the flow behaviour is presented through several case studies, showing how a simulation assuming Newtonian fluid characteristics differs from one using tailings rheology data to estimate non-Newtonian fluid behaviour. The results from the case studies are summarised in Table 1.

Table 1 Case study of Newtonian and non-Newtonian results

\begin{tabular}{cccccccc}
\hline Case & $\begin{array}{c}\text { Scenario } \\
\text { material }\end{array}$ & $\begin{array}{c}\text { Failure } \\
\text { type }\end{array}$ & $\begin{array}{c}\text { Maximum } \\
\text { flow depth } \\
(\mathbf{m})\end{array}$ & \multicolumn{5}{c}{ Approximate arrival time (hours) } \\
\hline 1a & Newtonian & Flood & 30 & 0.4 & 0.4 & 0.5 & - \\
\hline 1b & Non-Newtonian & induced & 25 & 0.8 & 1.0 & 1.0 & - \\
\hline 2a & Newtonian & Sunny & 30 & 0.4 & 0.4 & 0.6 & \\
\hline 2b & Non-Newtonian & day & 25 & 1.0 & 1.5 & 1.4 & - \\
\hline 3a & Newtonian & Flood & 15 & 0.7 & 0.8 & 1.0 & 1.0 \\
3b & Non-Newtonian & induced & 15 & 1.3 & 1.6 & 2.0 & 2.7 \\
\hline 4a & Newtonian & Sunny & 10 & 0.8 & 0.8 & 1.0 & 1.0 \\
\hline 4b & Non-Newtonian & day & 10 & 7.5 & 10.0 & - & - \\
\hline
\end{tabular}

As shown in Table 1, assuming tailings material behaves as a Newtonian fluid it typically results in faster travel times than that where the material's non-Newtonian characteristics are considered. The results further indicate that flow depths at points of interest are generally higher for Newtonian flows, which would result 
in a conservative outcome for stream power and subsequent damage estimations. However, careful consideration of these results is required when used for engineering of mitigation measures.

It is the authors experience that tailings rheology and release volume also have a noticeable impact on the results in a tailings dam failure study and due care should be placed in estimating these parameters and testing their sensitivities.

\section{$4 \quad$ Conclusions}

This paper presented a number of advances as well as a number of key inputs for the completion of dam failure impact assessments for tailings dams. Through the use of case studies of projects completed by the authors, it was shown that inundation results are very different for Newtonian and non-Newtonian dam break assessments, of which non-Newtonian model results show that Newtonian modelling vastly overestimates impacted areas. The flow behaviour was taken as an example of the many sensitivities in these complex analyses.

Further studies in this field are being undertaken to explore the development of meaningful dam break parameters for non-Newtonian failures, specifically for peak discharge rate, breach geometry and breach development time. It is unclear at this stage if these studies would result in an approach to obtain meaningful calibration parameters. Studies are also required to assess the impact of geomorphological changes as a result of the breach, and if changes to the floodplain or main channel through erosion of the natural soils or through deposition of entrained material would be relevant.

It is expected that advances in computational flow dynamics modelling software will continue and that more complex modelling could be undertaken in the future.

\section{Acknowledgements}

We thank Golder Associates Australia and Canada for their support and allowing us to use their resources, including CFD modelling software FLOW-3D ${ }^{\circledR}$, in writing this paper.

\section{References}

Australian National Committee on Large Dams (ANCOLD) 2012, Guidelines on Tailings Dams - Planning, Design, Construction, Operation and Closure, May 2012.

Blight, GE \& Bentel, GM 1983, 'The behaviour of mine tailings during hydraulic deposition', Journal of the South African Institute of Mining and Metallurgy, iss. 4.

Blight, GE \& Fourie, AB 2003, A Review of Catastrophic Flow Failures of Deposits of Mine Waste and Municipal Refuse, University of the Witwatersrand, Johannesburg.

CDA 2013, Dam Safety Guidelines 2007 (2013 Edition), CDA, Toronto

Chabbra, RP \& Richardson, JF 1999, Non-Newtonian Flow in the Process Industries, 1st edn, Butterworth-Heinemann, Oxford.

Clemente, JLM, Snow, RE, Bernedo, C, Strachan, CL \& Fourie, AB 2013, 'Dam break analysis applied to tailings dams: USSD workshop summary and perspectives, Proceedings of the 33rd Annual USSD Conference, p. 31.

Department of Environment and Energy 1999, Environment Protection and Biodiversity Conservation (EPBC) Act, Australian Government, viewed 6 October 2018, http://www.environment.gov.au/epbc

Flow Science, Inc. 2018, FLOW-3D ${ }^{\circledR}$, ver 11.2, computer software, Flow Science, Inc., Santa Fe, https://www.flow3d.com

Fontaine, D \& Martin, V 2015, 'Tailings mobilization estimates for dam breach studies', Proceedings of Tailings and Mine Waste 2015, pp. 343-356.

Horsley, RR \& Snow, RJ 1988, 'The rheology of some Australian mine tailings', in H Giesekus \& MF Hibberd (eds), Progress and Trends in Rheology II, Steinkopff, Heidelberg.

Ker, P 2016, 'BHP takes a global approach to dam standards', Australian Financial Review, viewed 7 October 2018, https://www.afr.com/business/mining/bhp-takes-a-global-approach-to-dam-standards-20160901-gr6jpe

Larrauri, P \& Lall, U 2018, 'Tailings dams failures: updated statistical model for discharge volume and runout', Environments Journal, vol. 5, no. 28 , https://doi.org/10.3390/environments5020028

Martin, V \& Akkerman, A 2017, 'Challenges with conducting tailings dam breach studies', 85th Annual Meeting of International Commission on Large Dams, Prague, Czech Republic, July 3-7.

Marwa, C, Haythem, B, Ezahra, S \& Mohamed, A 2014, 'Image processing application on graphics processors', International Journal of Image Processing, vol. 8, iss. 3. 
Mehta, D, Radhakrishnan, A, van Lier, J \& Clemens, F 2018, 'A wall boundary condition for the simulation of a turbulent non-Newtonian domestic slurry in pipes', Water, vol. 10, no. 2, p. 124.

Mining for Sustainable Development Programme (M4SD) 2017, Corruption Risks: Mining Approvals in Australia, Mining for Sustainable Development Programme, Transparency International, viewed 7 October 2018, https://transparency.org.au/ tia/wp-content/uploads/2017/09/M4SD-Australia-Report_Final_Web.pdf

More, M 2011, Development of a High-resolution 1D/2D Coupled Flood Simulation of Charles City, Master of Science thesis, University of lowa, lowa City.

Robertson, PK 2010, 'Evaluation of flow liquefaction and liquefied strength using the cone penetration test', Journal of Geotechnical and Geoenvironmental Engineering, vol. 136, pp. 842-853.

Rourke, H \& Luppnow, D 2015, 'The risks of excess water on tailings facilities and its application to dam-break studies', Tailings and Mine Waste Management for the 21st Century, The Australasian Institute of Minining and Metallurgy, Melbourne.

Strauss, AJ, Martin, V, Fontaine, D \& Cathcart, J 2016, 'Key steps for conducting tailings dam breach studies', International Symposium on Appropriate Technology to Ensure Proper Development, Operation and Maintenance of Dams in Developing Countries, South African National Committee on Large Dams, Pretoria. 